\title{
Influence of the lubricant on the endurance of steel ropes operating in corrosive environments
}

\author{
V.Yu. Sholom ${ }^{\dagger, 1,2}$, O. L. Kramer, ${ }^{1,2}$, V.P. Golovin ${ }^{1,2}$, O. P. Kornilova ${ }^{1,2}$, \\ A. N. Abramov ${ }^{1,2}$, R.F. Vagapov ${ }^{2}$ \\ †rosoil@rosoil.ru \\ ${ }^{1}$ Ufa State Aviation Technical University, Ufa, 450008, Russia \\ ${ }_{2}^{2}$ “Technopark KhTTs UAI-ROSOIL”, Ufa, 450057, Russia
}

The paper compares the results of endurance tests of steel ropes manufactured in accordance with GOST 2688-80, according to the standard method (GOST 2387-80 "Steel ropes. Endurance test method") without exposure to an aggressive environment and the test results according to the developed extended method, taking into account operating conditions in corrosive environments, in particular marine and freshwater environments. It was found that the periodic impact of sea water on the rope many times (from 2.5 to 9.5 times) reduces the wear resistance of the rope, depending on the lubricant used, when compared with tests according to the standard method and proportionally reduces its technical resource. It is shown that the impact of fresh water, as well as sea water, greatly reduces the wear resistance of the rope, but in somewhat smaller limits. On the basis of experimental studies, it has been shown that the compositions of lubricants, which ensured the maximum wear resistance of the rope according to the tests according to the standard method, showed the worst results when tested with the action of sea water. In this regard, it can be stated that the standard technique does not allow accurately predict the durability of ropes under special operating conditions (in sea and fresh water), which can lead to unreasonable, more than 9 times, reduction of the life of the rope. The complex of the studies carried out showed that when testing steel ropes for endurance, as well as when choosing the most effective rope lubricant, one should give preference to the test results according to the method proposed in the work, which takes into account the effect of a corrosive environment.

Keywords: endurance, rope lubricant, steel rope, testing.

УДК: 620.199

\section{Влияние смазочного материала на износостойкость стальных канатов, эксплуатирующихся В коррозионно-активных средах}

\author{
Шолом В. Ю. ${ }^{\dagger, 1,2}$, Крамер О. Л. ${ }^{1,2}$, Головин В. П. ${ }^{1,2}$, Корнилова О. П., ${ }^{1,2}$ \\ Абрамов А.Н. ${ }^{1,2}$, Вагапов Р. $\Phi .{ }^{2}$ \\ ${ }^{1}$ Уфимский государственный авиационный технический университет, Уфа, 450008, Россия \\ ${ }_{2}$ «ехнопарк ХТЦ УАИ-Росойл», Уфа, 450057, Россия
}

В работе сопоставляются результаты испытаний на износостойкость стальных канатов, изготовленных по ГОСТ 2688-80, по стандартной методике (ГОСТ 2387-80 «Канаты стальные. Метод испытания на выносливость») без воздействия агрессивной среды и результаты испытаний по разработанной расширенной методике, учитывающей условия эксплуатации в коррозионно-активной среде, в частности в морской и пресной воде. Установлено, что периодическое воздействие морской воды на канат многократно (от 2.5 до 9.5 раз) снижает износостойкость каната в зависимости от используемого смазочного материала, при сопоставлении с испытаниями по стандартной методике и пропорционально уменьшает его технический ресурс. Показано, что воздействие пресной воды, так же, как и морской воды многократно снижает износостойкость каната, но в несколько меньших пределах. На основании экспериментальных исследований показано, что композиции смазочных материалов, которые обеспечили максимальную износостойкость каната по ГОСТ 2688-80, при испытаниях с воздействием морской воды показали наихудшие результаты. В этой связи можно заявить, что стандартная методика не позволяет точно прогнозировать 
износостойкость канатов при особых условиях эксплуатации (в морской и пресной воде), что может приводить к необоснованному, более чем в 9 раз, снижению срока службы каната. Комплекс проведенных исследований показал, что при проведении испытаний стальных канатов на износостойкость, а также при выборе наиболее эффективного канатного смазочного материала, следует отдавать предпочтение результатам испытаний по предложенной в работе методике, учитывающей периодическое воздействие влаги.

Ключевые слова: износостойкость, канатный смазочный материал, стальной канат, испытания.

\section{1. Введение}

Вопросам исследования износостойкости стальных канатов при их эксплуатации посвящено много работ [1-5]. Одним из эффективных способов повышения срока службы стальных канатов является применение смазочных материалов. Основное назначение смазочного материала в стальном проволочном канате - это снижение трения и износа трущихся поверхностей, а также защита от коррозии в процессе эксплуатации. Поэтому, при изготовлении каната, все элементы его конструкции: сердечник, пряди, межпрядные и межпроволочные пространства тщательно покрываются и заполняются специальными канатными смазочными материалами (CM) [6-11]. Наличие СМ существенно повышает износостойкость стального каната и, соответственно, технический ресурс его эксплуатации [12-18].

В зависимости от назначения и условий эксплуатации каната используются различные СМ. В то же время производители канатов, с целью оптимизации производства, стремятся использовать наиболее универсальные СМ, которые обеспечивают защиту от износа и коррозии в максимально широком диапазоне назначений и условий эксплуатации изделия, что не всегда оправдано.

В статье [19] предложена методика ускоренных стендовых испытаний канатов на износостойкость и показано, что периодическое воздействие коррозионноактивной среды многократно уменьшает износостойкость стальных канатов различных конструкций, в которых ни сердечник, ни пряди, ни канат в целом не смазывались и не пропитывались смазочными материалами.

В данной статье рассматривается влияние различных смазочных материалов, применяемых при изготовлении канатов на российских предприятиях, на износостойкость каната при периодическом воздействии морской и пресной воды в сравнении со стандартными испытаниями (без воздействия влаги).

\section{2. Материалы и методы исследований}

Для сравнительных испытаний были отобраны образцы отечественных и зарубежных канатных СМ, применяющихся российскими металлургическими предприятиями, и предназначенных для аналогичных условий применения. До испытаний допускались только те CM, которые полностью соответствуют требованиям российских производителей канатов.

Воздействие коррозионно-агрессивной среды моделировалось периодическим окунанием испытуемого участка каната в жидкость при каждом цикле испытания.
Для этого пробежная машина дополнительно оснащена емкостью с жидкостью Рис. 1.

Схема испытаний образца каната показана на Рис. 1. Образцы канатов диаметром 5.6 мм, изготовленные по ГОСТ 2688-80, пропитывались различными СМ и испытывались на пробежной машине в соответствии с ГОСТ 2387-80 «Канаты стальные. Метод испытания на выносливость» [20].

Испытания проводились при скорости вращения барабана 120 колебаний в минуту, обеспечивающей возвратно-поступательные перемещения образца на длине 350 мм. Нагрузка на одну ветвь каната составляла $245 \mathrm{H}$. Сменные ролики диаметром 55 мм обеспечивали изгиб образца на $90^{\circ}$. Диаметр сменных роликов и нагрузка на одну ветвь каната выбирались в зависимости от диметра каната по ГОСТ 2172-80 «Канаты стальные авиационные. Технические условия» [21].

Износостойкость стального каната оценивалась по количеству перегибов образца каната до его полного разрушения.

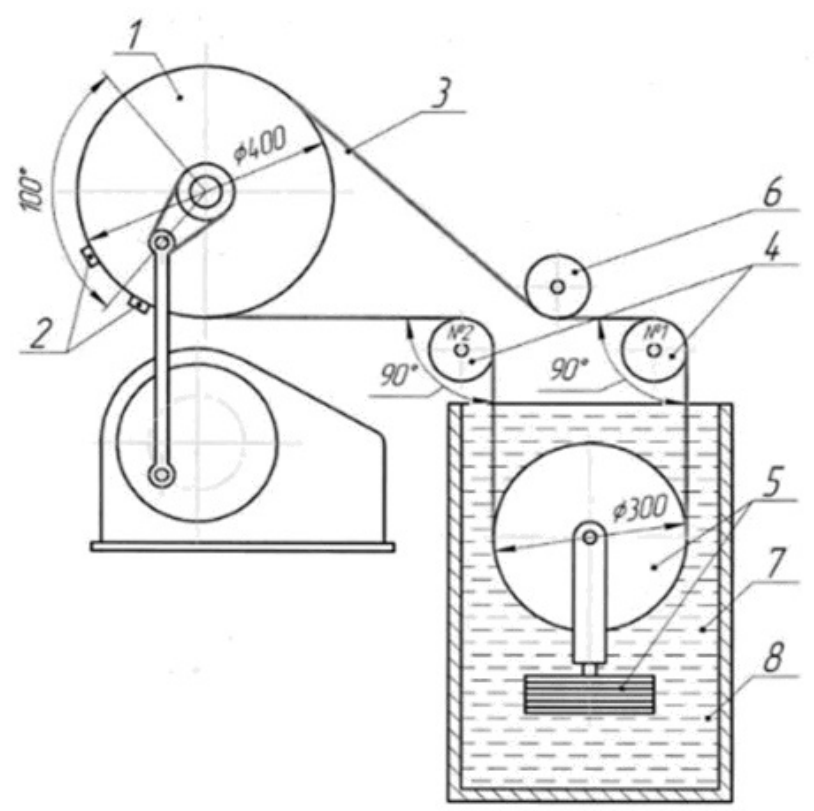

Рис. 1. Машина для испытания канатов на износостойкость в жидких средах: (1) - ведущий барабан, (2) - зажимы для крепления образца каната, (3) - образец каната, (4) сменные ролики, (5) - грузовой ролик, (6) - направляющий ролик, (7) - съемная емкость, (8) - жидкая среда.

Fig. 1. Endurance rope testing machine in liquid environments: (1) - lead drum, (2) - rope fastening clips, (3) - a sample rope, (4) - interchangeable rollers, (5) - cargo roller, (6) - guide roller, (7) - removable capacity, (8) - liquid medium. 
Следует отметить, что при выполнении данной работы для изготовления (нарезки) образцов потребовалось несколько километров каната, изготовленного по спецзаказу, не смазанного и не пропитанного в процессе изготовления. Поэтому часть образцов канатов были изготовлены из разных бухт, давали разброс значений при испытаниях на износостойкость, но не более $20 \div 25 \%$ в большую или меньшую сторону. (Как правило, даже в пределах одной бухты, по ее длине, может меняться разрывная прочность каната в пределах, установленных ГОСТом. Соответственно меняется и показатель износостойкости при испытаниях.) При усталостных испытаниях такой разброс результатов допустим. Поэтому испытывались по 15 образцов в каждой серии испытаний. Статистическая обработка результатов испытаний производилась в соответствии п. 4.2 ГОСТ-Р 8.736-2011 «Измерения прямые многократные. Методы обработки результатов измерений». Доверительная вероятность 0.95 .

Учитывая эти обстоятельства, в работе не указываются конкретные названия смазочных материалов и их производители, а приведенные результаты носят обобщающий характер, с допустимыми для усталостных испытаний погрешностями.

\section{3. Результаты}

На диаграмме (Рис. 2) приведены результаты испытаний канатов в соответствии с ГОСТ 2387-80, то есть без принудительного воздействия коррозионно-агрессивных сред. Средние значения показателей выносливости расположены в порядке возрастания от минимального до максимального. Соответствующую нумерацию получили и смазочные материалы (L1-L8), которыми были пропитаны образцы канатов до начала испытаний.

Видно (Рис. 2), что использование смазочного материала значительно повышает выносливость каната при работе без воздействия агрессивных сред (от 1.7 до 3.4 раз). Большинство рассмотренных СМ характеризуются близкой износостойкостью, составляющей 200000-300000 перегибов до разрушения. Так же следует отметить, что при испытаниях для каждого смазочного материала отмечается большой разброс значений, характерный для усталостных испытаний. Показавшие наибольшею износостойкость образцы L7 и L8 обладают в то же время наименьшей стабильностью результатов.

Результаты испытаний канатов с периодическим воздействием пресной воды представлены на следующей диаграмме (Рис. 3).

При испытаниях в пресной воде происходит заметное снижение (до 3 и более раз) износостойкости канатов как без СМ, так и в его присутствии. Тем не менее, все использованные СМ повышают износостойкость канатов в пресной воде минимум в 1.5-2 раза по сравнению с испытаниями без смазочного материала (Рис. 3). Причем L4 увеличивает срок службы каната почти в 3.5 раза. Образцы с наилучшей выносливостью по стандартной методике L7 и L8 при воздействии воды показывают одни из худших результатов.
Результаты испытаний канатов с периодическим воздействием коррозионно-активной среды (морской воды) представлены на Рис. 4.

Коррозионно-агрессивная среда (морская вода) еще более снижает износостойкость канатов. Смазочные материалы L8 и L7 обеспечили максимальную выносливость каната в обычных условиях, но при испытаниях с воздействием морской воды показали наихудшие результаты.

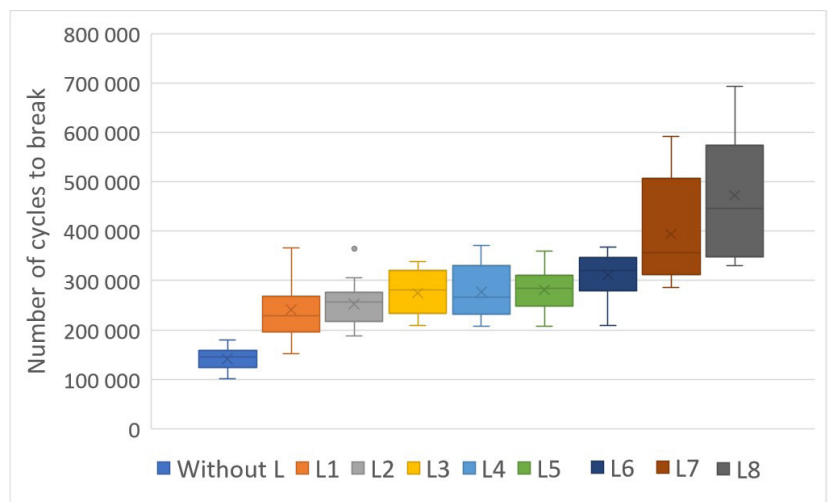

Pис. 2. (Color online) Результаты испытаний канатов в обычных условиях.

Fig. 2. (Color online) Results of the steel ropes tests under normal conditions.

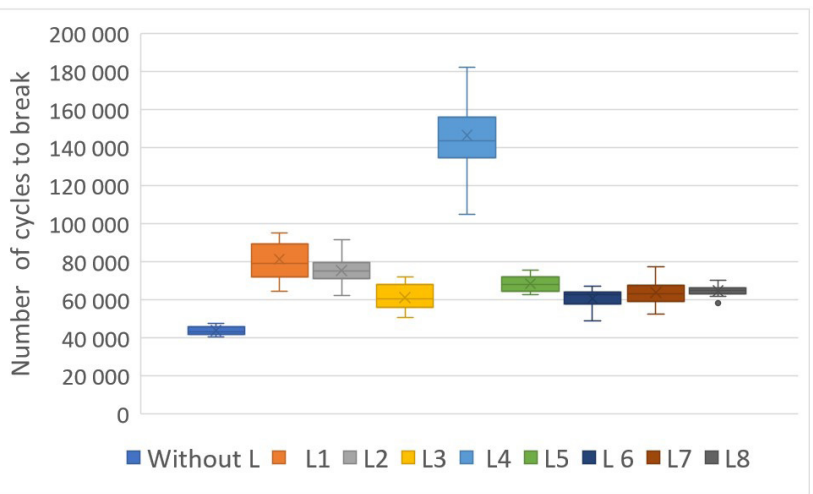

Puc. 3. (Color online) Результаты испытаний канатов в пресной воде.

Fig. 3. (Color online) The results of the ropes tests in the water.

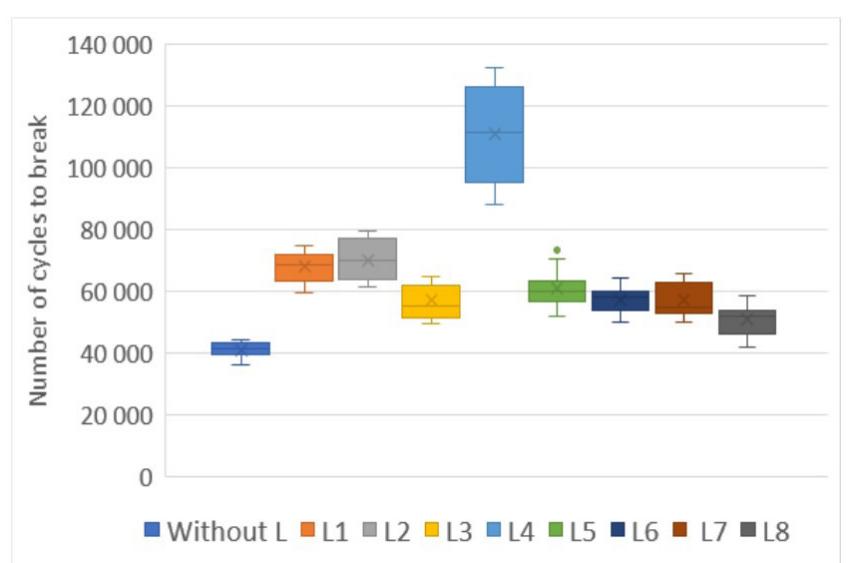

Puc. 4. (Color online) Результаты испытаний канатов в морской воде.

Fig. 4. (Color online) Results of the hawsers tests in the sea water. 
Сопоставительный анализ результатов, полученных при испытаниях без воздействия коррозионно-агрессивной среды и в присутствии последней, дают основание заявить, что износостойкость канатов сильно зависит от присутсвия влаги. СМ, показывающие превосходные результаты в сухих условиях, могут показывать плохие результаты при наличии воды. Поэтому, учитывая, что периодическое воздействие влаги характерно практически в любых условиях эксплуатации канатов, при проведении ресурсных испытаний следует отдавать предпочтение результатам испытаний по предложенной в работе методике.

\section{4. Выводы}

1. Установлено, что периодическое воздействие морской воды многократно (от 2.5 до 9.5 раз), снижает износостойкость каната, в зависимости от используемого смазочного материала, по отношению к значениям, определенным в испытаниях по ГОСТ 2387-80 «Канаты стальные. Метод испытания на выносливость» и пропорционально уменьшает его технический ресурс.

2. Воздействие пресной воды, так же, как и воздействие морской воды многократно снижает износостойкость каната, но в несколько меньших пределах (на 7-29\%) по отношению к испытаниям в морской воде.

3. Смазочные материалы L8 и L7 обеспечили максимальную износостойкость каната в стандартных испытаниях по ГОСТ 2387-80, но при испытаниях с воздействием морской воды показали наихудшие результаты.

4. Учитывая, что периодическое воздействие влаги характерно практически в любых условиях эксплуатации канатов, при проведении ресурсных испытаний следует отдавать предпочтение результатам испытаний по предложенной в работе методике.

\section{Литература / References}

1. Y. Peng, X. Chang, S. Sun, Z. Zhu, X. Gong, S. Zou, W. Xu, Z. Mi. Wear. 400 - 401, 194 (2018). Crossref

2. Y. Chen, F. Meng, X. Gong. Wear. 368-369, 470 (2016). Crossref

3. Y. Peng, X. Chang, Z. Zhu, D. Wang, X. Gong, S. Zou, S. Sun, W. Xu. Wear. 368 - 369, 423 (2016). Crossref

4. L. Xiang, H. Y. Wang, Y. Chen, Y. J. Guan, L. H. Dai. Int. J. Solids Struct. 129, 103 (2017). Crossref

5. A.P. Koshkin, G.D. Trifanov. The ropes for lifting plants. Perm, Publisher of the Perm NRPU (2014) 107 p. (in Russian) [А.П. Кошкин, Г.Д. Трифанов. Канаты для подъемных установок. Пермь, Издво ПермНИПУ (2014) 107 с.]

6. V.N. Novikov, V.V. Tarasov, E. A. Kalentyev, V.A. Postnikov. Works of GOSNITI. 109, 98 (2012). (in Russian) [В.Н. Новиков, В.В. Тарасов, Е.А. Калентьев, B. А. Постников. Труды ГОСНИТИ. 109, 98 (2012).]
7. V.Yu. Sholom, V.S. Schernakov, V.V. Nikolskaya, M.R. Yusupov, O.L. Kramer. KSHP-OMD. 11, 44 (2018). (in Russian) [В.Ю. Шолом, В.С. Жернаков, В.В. Никольская, М. Р. Юсупов, О.Л. Крамер. КШП ОМД. 11, 44 (2018).]

8. O.L. Kramer, N.V. Saveleva, A.S. Trofimov, V.V. Nikolskaya. Friction and lubricant in machines and mechanisms. 5, 30 (2014). (in Russian) [О.Л. Крамер, Н.В. Савельева, А.С. Трофимов, В.В. Никольская. Трение и смазка в машинах и механизмах. 5, 30 (2014).]

9. K. Wire. Ropes. Berlin-Heidelberg, Springer Verlag (2007) 322 p.

10. M. Giglio, A. Manes. Eng. Fail. Anal. 12, 549 (2005). $\underline{\text { Crossref }}$

11. E. V. Marchenko, S.I. Popov, Yu.V. Marchenko, N.S. Dontsov. Sbornik trudov mezhdunarodnogo nauchnogo simpoziuma tekhnologov-mashinostroiteley. Rostovon-Don (2017) p. 131. (in Russian) [Э.В. Марченко, С.И. Попов, Ю.В. Марченко, Н.С. Донцов. Сб. трудов Междунар. научн. симпозиума технологовмашиностроителей. Ростов-на-Дону (2017) с. 131.]

12. V.I. Ponhmursky. Korrozionnaya ustalost' metallov. Moscow, Metallurgiya (1985) 207 p. (in Russian) [В.И. Похмурский. Коррозионная усталость металлов. Москва, Металлургия (1985) 207 с.]

13. M.G. Ivanov, G.M. Chudakov. Scientific works of KubGTU. 4, 152 (2015). (in Russian) [М.Г. Иванов, Г. М. Чудаков. Научные труды КубГТУ. 4, 152 (2015).]

14. Patent RF №2440319, 27.12.2017. (in Russian) [Патент РФ № 2440319, 27.12.2017.]

15. J. J. Evans, I. M.L. Ridge, C.R. Chaplin. J of Strain Analysis. 36 (2), 219 (2001). Crossref

16. H. Mouradi, A. El Barkany, A. El Biyaali. Journal of Engineering and Applied Sciences. 11 (6),1206 (2016).

17. D. Elata, R. Eshkenazy, M.P. Weiss. Int. J. Solids Struct. 41, 1157 (2004). Crossref

18. L. M. Shkolnik. Metodika ustalostnykh ispytaniy. Moscow, Metallurgiya (1978) 304 p. (in Russian) [Л. М. Школьник. Методика усталостных испытаний. Москва, Металлургия (1978) 304 с.]

19. A.N. Abramov, V.Yu. Sholom, O.L. Kramer, V.P. Golovin. Letters on Materials. 10 (2), 195 (2020). (in Russian) [А.Н. Абрамов, В.Ю. Шолом, О.Л. Крамер, В.П. Головин. Письма о материалах. 10 (2), 195 (2020).] Crossref

20. GOST 2387-80 "Steel ropes. Endurance Test Method". Moscow, Publishing house of standards (1980). (in Russian) [ГОСТ 2387-80 «Канаты стальные. Метод испытания на выносливость». Москва, Издательство стандартов (1980).]

21. GOST 2172-80 "Steel Aviation Ropes. Technical conditions". Moscow, Publishing house of standards (1980). (in Russian) [ГОСТ 2172-80 «Канаты стальные авиационные. Технические условия». Москва, Издательство стандартов (1980).] 